through five. In every case like this, whore forces are in equilibrium on a system, we can imagine a motion given, every point moving according to the geometrical circumstances. Let us imagine such a motion. When two forces act on a system and keep it at rest, multiply the space through which the point of application of each force moves, referred to the line in which the force acts, by the measure of the force. When there is equilibrium the resulting quantities are equal and of opposite signs. The one child weighing 50 lbs. rises vertically through 7 inches, and we may call the product 350 inch-lbs. upwards. The 70 lbs. child moves in the same time 5 inches downwards, and the product, which is $35^{\circ}$ inchlbs. downwards, is equal and opposite to the other. If there is equilibrium it must always be so; if it is so there must be equilibrium. It was to Galileo that we owe this most fruitful of statical principles. It can easily be extended to the case when any number of forces act at any number of points on a body or a system, but it was not till a century later that John Bernouilli could state it in all its generality, or show how admirably it serves as a sufficient basis for the whole theory of equilibrium.

These laws of falling bodies and of virtual velocities marked the greatest advance in mechanical science since the world began. The nature of the earth's common action on all bodies at its surface had, in fact, been ascertained. The question that had been put directly to nature had been completely answered, and the answer was final.

The Peripatetics had a singular notion of what they called Inertia. According to them, a body had a natural tendency to move at a given speed straight towards the centre of the earth if it were heavy, and straight away from it if it were light. The continuance of that natural motion, in that direction, at that speed was ensured by inertia. Strike the body in that or in any other direction, and an immediate change takes place, but it is a change which disappears if the body is moving in a vacuum. In ordinary air it is kept up, because the air behind, from which the body is suddenly taken away when it is struck, instantly closes up, and strikes it like a spring which has been let go. At every new position it leaves air, and air springs after it to keep it going. As far as it was then possible, Galileo worked out the consequences of this theory and those of his own, which was that stated in Newton's first Law of Motion-that except where any external force operates, motion in any direction at a certain rate will continue indefinitely in that direction at the same rate. The result was that the old theory was proved to be wrong. As with the first law of motion, so with the second. It is substantially this, that when a force acts on a particle in motion, it produces the same effect in changing that motion as it would if, before it began to act, the body were at rest. Suppose a particle moving with a speed which may be described as ro feet per second northward and 8 feet per second eastward. Let a force suddenly act on it, the effect of which is to change its rate of going to $I 7$ feet per second northward and 13 feet per second eastward. The amount gained is an addition of speed of 7 feet per second northward and 3 feet per second eastward. Imagine the same force acting on a particle identical with the former, but initially at rest. It will make that particle begin to move from rest at the same rate of 7 feet per second northward and 3 feet per second eastward which it gained in the former motion. The effect in changing rate has been the same as if the body had been at rest, and the whole effect on the eastward direction has been the same as it would have been had there been nothing to affect it in a northerly direction.

It was through the combination of these two principles that Galileo was able to solve another and more difficult problem. Until they were verified by the success of millions of predictions founded on them, they were not so much principles as thcories or hypotheses. A fulfilled prediction of any complicated phenomenon raises the hypothesis on which it has been explained to the dignity of a probable truth. Let a bullet be started in an oblique direction at a certain speed-we can predict, by applying these two principles, the way in which it will move and the course it will follow. Let us take one which is sent off at a rate of speed compounded of 32 feet per second vertical and 20 feet per second horizontal. At every point of its path, it will keep both these rates except so far as gravity changes them, and gravity will do by it as a moving body just what it would do by a body starting from rest. To the latter it would give a downward speed of 32 feet per second in a second. In a second it will give just enough downward speed, therefore, to annihilate the upward speed of the bullet. After a second, it will have ceased to have any upward speed, but it will go on with the horizontal speed of 20 feet per second. In its first second the bullet has moved away from its startingpoint 20 feet in a horizontal direction and 16 feet upward, because a fall of 16 feet from rest is needed to generate that velocity of 32 feet per second downward, which is wanted to destroy the upward velocity of the amount with which it started. At the end of the first second it has reached its new position by a certain path. Till the bullet comes to the ground again another second will suffice, during which it will fall through $\mathrm{I} 6$ feet vertically, and acquire a speed of 32 feet per second downward as it started with 32 feet per second upward, and it will move horizontally 20 feet further from the starting-point. When the second second closes, the particle has again reached the ground by a path which is the left-handed facsimile of that by which it rose.

There are thus three measurable things, all consequences of our fundamental laws. Does the bullet rise I6 feet? does it strike the ground 40 feet away from where it started? does it take 2 seconds to do it in? Nature answers that all these things are so. If we take some means of making the bullet record or picture its path on a board or paper we shall have a still completer answer to the question. Galileo's mathematics were enough to show him that if these two laws were true the curve described must be a parabola-except so far as it is slightly modified by the resistance of the air-and the parabola calculated is the parabola described. Such a proof is all but conclusive. Every point in the path really found has thus been predicted as the mathematical consequence of these two laws, and when this prediction is repeated and confirmed in every experiment, doubt vanishes, the laws are securely established, and the secret of nature has been found.

(To be continued.)

\section{JAMES CLERK MAXWELL, F.R.S.}

I AMES CLERK MAXWELL, whose premature deaty on Wednesday last week, science has to deplore, was born in 1831, being the only son of John Clerk Maxwell, Esq., of Middlebie, His grandfather was Captain James Clerk of Penicuik, whose two sons were the Right Hon. Sir George Clerk, Bart., of Penicuik, and the above-mentioned, John Clerk Maxwell. Captain James Clerk was a younger brother of Sir John Clerk of Penicuik, and on the death of the latter Sir George Clerk succeeded to the estate of Penicuik, while John succeeded to the estate of Nether Corsock, part of the Middlebie estate, which had come into the family through marriage in a previous generation with Agnes Maxwell. Along with this estate John Clerk assumed the family name of Maxwell. When James Clerk Maxwell was eight years old, his mother died, and his father, who had been called to the Scotch Bar, but never practised as an advocate, lived a retired life, devoting himself to the care of his estates, and of his son. 
James Clerk Maxwell was educated at the Edinburgh Academy, where he gained the Academical Club Medal for Geometry in 1845 , and the Silver Medal for Mathematics in 1847 . In 1848 his mother's brother, John Cay, of Edinburgh, took him to see William Nicol, who showed him the colours exhibited by polarised light after passing through unannealed glass, \&c. This visit seems to have given the first impulse towards his researches in optics. On his return he constructed a polariscope with glass reflectors. The framework of the first was of cardboard, but a superior article was subsequently constructed by him in wood. Small lenses mounted in cardboard were employed when a conical pencil of light was required. By means of this instrument he examined the figures exhibited by pieces of tnannealed glass which he prepared himself, and with a camera iucida, and a box of water colours, he reproduced these figures on paper, taking care to sketch no outlines, but to shade off each coloured band imperceptibly into the next. Some of these water-colour drawings he forwarded to $\mathrm{Nicol}$, and was more than repaid by the receipt shortly afterwards of a pair of prisms prepared by Nicol himself. These prisms were always very highly prized by Prof. Maxwell. Once while at Trinity the little box containing them was carried off by his bed-maker during a vacation, and destined for destruction. The bed-maker died before term commenced, and it was only after a very diligent search that they were found among the late bed-maker's effects, which had been set aside as valueless. After this event the prisms were most carefully guarded, and about three weeks ago were deposited, at Professor Maxwell's request, in one of the show cases of the Cavendish laboratory. The study of the figures exhibited by unannealed glass in polarised light drew the attention of Clerk Maxwell more particularly to the equilibrium of elastic solids, a subject on which he has done some very valuable work.

After leaving the Edinburgh Academy James Clerk Maxwell entered the University of Edinburgh, where he soon won the esteem of Kelland, Forbes, and Gregory, under whom he studied and worked. In October, I850, he came to Cambridge, entering at Peterhouse. At this time his father does not seem to have been very sanguine respecting the advantages to be derived from a Cambridge course, but his opinion of the University rose considerably when in 1854 the examiners showed their appreciation of his son by making him Second Wrangler, and bracketing him as first Smith's Prizeman. Clerk Maxwell's first term in Cambridge does not seem to have been a very happy one. The Peterhouse men were all classics or pure mathematicians, and he could get no sympathy in his physical work. Finding himself comparatively without friends at the end of the term, he consulted his father and his college tutor, and by their advice migrated to Trinity on December I4th, I850, where, having a much larger number to select from, he not only found congenial spirits, but soon became looked up to as their leader by a set of admiring followers. In 1852, while an undergraduate at Trinity, he stayed for a few weeks at a country vicarage in Suffolk with the Rev. C. B. Taylor, a brother of a college friend. While there he was attacked by a serious illness, and the care and kindness with which he was nursed by Mr. and Mrs. Taylor never faded from his memory; it so impressed him with the power of love that it formed an important factor in the formation of the Christian character which all who knew regarded with an admiration akin to worship.

As above stated James Clerk Maxwell graduated as Second Wrangler and (bracketed) first Smith's Prizeman in 1854, having previously been elected a Foundation Scholar of his College. In 1855 he became a Fellow of Trinity, and in 1856 obtained the Professorship of Natural Philosophy in Marischal College, Aberdeen, which appointment he held till the fusion of Marischal College and King's College, when he, with other Professors, received a pension from the Crown. In 1858 he married Katherine, a daughter of Principal Dewar of Marischal College, thus vacating his fellowship at Trinity. In I 860 he succeeded Prof. Goodeve as Professor of Natural Philosophy and Astronomy in King's College, London, but after the death of his father he retired in 1865 to his estate in Scotland, where he subsequently carried out his father's plans for completing the house and offices at Glenlair. In 187 I he was invited by the Senate of the University of Cambridge to accept the Chair of Experimental Physics which had just been created, and on October $25^{\text {th }}$, I $87 \mathrm{r}$, he delivered his inaugural lecture as Professor of Experimental Physics in the University of Cambridge. At first the most important part of his work consisted in arranging the details of the Cavendish Laboratory which the Duke of Devonshire had offered to present to the University, and the building of which was personally superintended by Prof. Maxwell from first to last. The whole of the arrangements which render the Cavendish Laboratory so admirably adapted for Physical investigations, are due to the care and forethought of Frof. Clerk Maxwell. When the building had been completed and formally presented to the University, the Duke of Devonshire further signified his desire to provide it with a complete equipment of apparatus, and all this was procured under the personal supervision of the Professor. In 1872 he was elected Honorary Fellow of Trinity College, Cambridge.

During last winter Prof. Maxwell did not enjoy his usual health. In the spring he was unable to carry on his work with his accustomed vigour, but when he left Cambridge for Scotland his friends supposed that with mental rest and physical exercise his health would be restored, and did not regard his indisposition as other than temporary. In Scotland, however, his health did not improve, he suffered much pain and was unable to take his usual food. At length by the advice of his medical attendants, and of Prof. Saunders of Edinburgh, one of his former fellow-students, he returned to Cambridge in the beginning of October. Under Dr. Paget's care he at first made considerable improvement and some hopes were entertained of his recovery. $\mathrm{He}$, however, gradually became weaker, and when Dr. Humphry visited him in conjunction with Dr. Paget, it was plain that medical skill could only alleviate his suffering. He died at noon on Wednesday, November 5th, having retained the conscious possession of all his mental powers to the last.

General invitations were sent to all members of the electoral roll of the University to assemble in Trinity College Chapel at 430 P.M. on Monday, November Ioth, and were numerously accepted, especially by heads of houses (including the Vice-Chancellor), and by professors. About 4.45 P.M., the service was commenced by $\mathrm{Mr}$. Stanford playing the "Dead March" upon the organ. The remains of the late Professor were then carried into the chapel, preceded by the choir and the first part of the Burial Service read. This was followed by the Anthem "If we believe that Jesus died and rose again, even so them also which sleep in Jesus shall God bring with him. -... Wherefore comfort one another with these words." After the service the assembly followed the body to the great gate, whence it was conveyed to Scotland to be interred in the family burying-place at Corsock, Kirkcudbright.

Prof. Maxwell was appointed Foreign Honorary Member of the American Academy of Arts and Sciences of Boston in November, 1874 ; Member of the American Philosophical Society of Philadelphia in October, I875; Correspondent in the Mathematical Class to the Imperial Academy of Sciences, Göttingen, in December, 1875 ; Honorary Member of the New York Academy of Sciences in December, 1876 ; Associate of the Amsterdam Royal Academy of Sciences in April, 1877 ; and Corresponding Member of the Imperial Academy of Sciences, Vienna, 
in August, 1877. He was Fellow of the Royal Societies of London and Edinburgh, and of the Cambridge Philosophical Society, and a large contributor to the Transactions of each of these. In 1872 he was created Honorary LL.D. of Edinburgh, and on June 21, 1876, he received the honorary degree of D.C.L. at Oxford.

In 1860 the Rumford Medal of the Royal Society was awarded to Prof. Clerk Maxwell "for his Researches on the Composition of Colours, and other Optical papers." In his address on the presentation of the medal, MajorGeneral Sabine alluded to Prof. Maxwell's calculation showing the connection of the "mechanical strains to which elastic solids are subjected under certain conditions with the coloured curves which those solids exhibit in polarised light." He then alluded to the colour-top of Prof. Maxwell, and the colour-equations obtained from it, as well as the light it throws upon colour-blindness, concluding with these words :- "These researches for which the Rumford medal is awarded lead to the remarkable result that to a very near degree of approximation all the colours of the spectrum, and therefore all colours in nature, which are only the mixtures of these, can be perfectly imitated by mixtures of three actually attainable colours, which are the red, green, and blue, belonging respectively to three particular points of the spectrum."

While Professor of Physics at King's College, London, Maxwell was engaged as a member of the British Association Committee in the determination of the Absolute Unit of Electrical Resistance, and it was the comparison of electrical units which attracted a great part of his attention during his tenure of his Cambridge Professorship. He always spoke very highly of Faraday's "Experimental Researches," which he read very early in life, and to which he attributed some of his most useful ideas on electricity and electro-magnetism. In Clerk Maxwell Faraday found a mind constituted after the same plan as his own, but with the advantage of a mathematical training, which has made Prof. Maxwell capable of interpreting Faraday's bold realisations to the mathematical world. For Clerk Maxwell's own views of Faraday the reader may be referred to the article "Faraday," in the ninth edition of the "Encyclopædia Britannica."

It is impossible in a sketch like this to give anything but the most superficial view of a character so noble in all its aspects as that of Clerk Maxwell. As a professor he was wonderfully admired by those who were truly his disciples. He had not the power of making himself clearly understood by those who listened but casually to his pithy sentences, and consequently he was not a socalled popular lecturer; nor was he a most successful teacher of careless students. But when he had those about him who could enter into his mind, and, receiving the golden truths from his lips, could alloy them in such a way as to make them acceptable to the ordinary student, no better teacher could be desired, even for the most elementary instruction. His wonderful imagination was of great value, not only in supplying illustrations for didactic purposes, but in suggesting analogies and opening up new fields for research.

The pages of Blackwood's Magazine can testify to his talents as a poct; his sense of humour and his ready wit formed remarkable features in his character, in fact he seldom talked for many minutes without proroking at least a smile. (Some of the reviews lately contributed by him to NATURE may serve as illustrations.) He was well versed in all the literature of the day, and seemed to have investigated on his own account every system of philosophy. He took great interest in passing events, though he never indulged in political discussions. As an experimentalist he was too well known to require description; in that region of science which was his par excellence, viz., the domain of Molecular Physics, he stands without a rival. But there were other sides of his character which outshone even his scientific attainments. Such complete unselfishness and tender consideration as he exhibited for those around him, and especially for those under his control, are seldom to be met with. During the eight years that he held the chair of Physics in Cambridge, he never spoke a hasty word, even to his attendants. His self-sacrificing devotion to those he loved was the marvel of his friends. Though he never entered into theological controversy, and only occasionally in his scientific writings indicated in a sentence or two the side he took in ques. tions which have recently been brought prominently before the public by some of the more popular men of science, those who had an opportunity of seeing into his home-life knew him to be an earnest Christian. About three weeks ago he remarked that he had examined every system of Atheism he could lay hands on, and had found, quite independently of any previous knowledge he had of the wants of men, that each system implied a God at the bottom to make it workable. He went on to say that he had been occupied in trying to gain truth, that it is but little of truth that man can acquire, but it is something to "know in whom we have believed." His simple Christian faith gave him a peace too deep to be ruffed by bodily pain or external circumstances, and left his mind free to the last to contemplate all kinds of questions of general interest. One day not long before his death he had been puzzling himself for some time in vain endeavours to discover why Lorenzo ("Merchant of Venice," Act v. scene I), whose character was at least far from noble, says to Jessica-

" Look how the floor of heaven

Is thick inlaid with patines of bright gold :

There's not the smallest orb which thou beholdst

But in his motion like an angel sings,

Still quiring to the young-eyed cherubins ;

Such harmony is in immortal souls ;

But whilst this muddy vesture of decay

Doth grossly close it in, we cannot hear it."

We may quote one other example illustrating how the speculative character of his mind remained to the last. About five or six days before his death, when he was suffering from such extreme weakness that he could say very little, after lying motionless with his eyes closed for some time, he presently looked up and remarked, "Every good gift and every perfect gift is from above, and cometh down from the Father of lights, with whom is no vari. ableness, neither shadow of turning.' Do you know that is a hexameter?

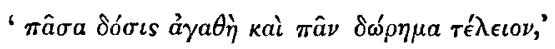

I wonder who composed it."

His knowledge of hymns and hymn-writers was very extensive, and he took great pleasure during his illness in reciting from memory some of his favourites among the writings of Richard Baxter, George Herbert, and others.

To attempt to give any adequate idea of his contri. butions to science in a sketch like the present would be but to mislead the reader. His great work on "Electricity anc Magnetism," the second edition of which is now in the press, is the admiration of mathematical physicists. More generally known are his treatise on the Theory of Heat, and his little text-book entitled "Matter and Motion" which was published by the S.P.C K. One of his earliest papers on the "Theory of Rolling Curves," was communicated to the Royal Society of Edinburgh by Professor Kelland, and read on February 19, 1849, when Clerk Maxwell was an Edinburgh student barely eighteen years of age. His paper on the "Equilibrium of Elastic Solids," above alluded to, was read before the same society on February 18, 1850. His paper on the "Transformation of Surfaces by Bending" was read before the Cambridge Philosophical Society on March 13 , 1854, about two months after taking his degree. This 
was followed in December, 1855 , and February, $185^{6}$, by papers on "Faraday's Lines of Force." In 1857 he obtained the Adams Prize, in the University of Cambridge, for his paper on the "Motions of Saturnian Rings." His paper on the "Theory of Compound Colours, and the Relations of the Colours of the Spectrum," which was chiefly instrumental in gaining the Rumford Medal, was read before the Royal Society on March 22, 186o. His "Dynamical Theory of the Electromagnetic Field," including a brief sketch of the Electromagnetic Theory of Light, was read before the Royal Society on December 8, I 864. The results of Clerk Maxwell's experiments on "The Viscosity and Internal Friction of Air and other Gases," were made known to the Royal Society in the Bakerian Lecture read, February 8, 1866. Then follow his Royal Society papers "On the Dynamical Theory of Gases," in May, I866, and "On a Method of Making a direct Comparison of Electrostatic with Electromagnetic Force, with a Note on the Electromagnetic Theory of Light," in June, 1868. Lately he took great interest in Graphical Statics, and contributed a long paper "On Reciprocal Figures, Frames and Diagrams of Forces," to the Royal Society of Edinburgh, in December, 1869. Among his most recent papers are a paper on "Stresses in Rarefied Gases arising from Inequalities of Temperature," read before the Royal Society on April I I, I878, and a paper on "Boltzmann's Theorem," read before the Cambridge Philosophical Society. It would take too long to enumerate his articles and reviews published in the $P$ hilosophical Magazine and in NATURE. His contributions to the ninth edition of the "Encyclopæedia Britannica" include the articles "Atom," "Attraction," "Capillary Action," "Constitution of Bodies," "Diagrams," "Diffusion," "Ether," "Faraday," and "Harmonic Analysis." "Harmonic Analysis" was the last article he wrote.

One of the most remarkable of his works is the recently-published volume of the Electrical Researches of the Hon. Henry Cavendish, of which Prof. Maxwell is the editor. The MSS, are in the possession of the Duke of Devonshire, and are now at Chatsworth. They were entrusted by him to Prof. Maxwell shortly after the completion of the Cavendish Laboratory. Some of Cavendish's experiments were repeated by Prof. Maxwell with all the appliances of modern apparatus, and others were carried out by his pupils.

Most of the apparatus which he employed in his researches has been presented by Prof. Clerk Maxwell to the Cavendish Laboratory, together with many of his books. He always-regarded the laboratory with great affection, and the University owes much to his liberality. One of the most interesting pieces of his handy-work now preserved in the laboratory is a plaster model of Prof. Willard Gibbs's thermodynamic surface, described in the fourth edition of "Maxwell's Theory of Heat." All the lines on the surface are drawn by his own hand, many of them being mapped out by placing the surface obliquely in the sunshine and marking the boundary between light and shade. Another valuable model constructed while Prof. Maxwell was at Cambridge is his dynamical illustration of the action of an induction coil in which two wheels represent by their rotation the primary and secondary currents respectively, the wheels being connected through a differential gearing to which a body of great moment of inertia is attached, the rotation of which represents the magnetism of the coil. A friction break represents resistance, and a spring may be attached to the secondary wheel to represent the capacity of a condenser placed in the secondary circuit. Among other valuable pieces of apparatus presented by Prof. Maxwell to the laboratory are the receiver, plates, and inertia bar employed in his researches on the viscosity of air and other gases, his colour-top, portions of the "colour-box," including the variable slits, with the wedge for measuring their width, a polariser and analyser made of thin films of stretched gutta percha, the mechanism for illustrating the motion of Saturnian rings, a real image stereoscope, and the dynamical top, whose moments of inertia about three axes, which are at right angles to each other, can be so varied by means of screws that the axis of rotation can be made that of greatest or of least moment of inertia. When the axis of rotation is the mean axis, the motion of the top is, of course, unstable. When Prof. Maxwell came to Cambridge in 1857 to take his M.A. degree, he brought this top with him from Aberdeen. In the evening he showed it to a party of friends in college, who left the top spinning in his room. Next morning he espied one of these friends coming across the court, so jumping out of bed, he started the top anew. and retired between the sheets. The reader can well supply the rest of the story for himself. It is only necessary to add that the plot was completely successful.

Prof. Clerk Maxwell's papers will be placed in the hands of Prof. Stokes, who is one of his executors, in order that they may be published or catalogued and preserved in such a way as to be readily available to those wishing to consult them.

The death of James Clerk Maxwell is a loss to his University and to the world too great for words. He rests from his labours, but his works will follow hin.

\section{WM. GARNETX}

\section{NOTES}

THE following is the list of officers to be proposed at the anniversary meeting of the Royal Society on December $I$ :President-William Spottiswoode, M.A., D.C.L., LL.D Treasurer-John Evans, D.C.L., LL.D., V.P.S.A. Secretaries-Prof. George Gabriel Stokes, M.A., D.C.L., LL.D., Prof. Thomas Henry Huxley, LL.D. Foreign SecretaryProf. Alexander William Williamson, Ph.D. Other Members of the Council-George Busk, V.P.L.S., Prof. Arthur Cayley, LL.D., Major-General Henry Clerk, R.A., Edwin Dunkin, F.R.A.S., Augustus G. Vernon Harcourt, F.C.S., Sir Joseph Dalton Hooker, C.B., K.C.S.I., D.C.L., John Whitaker Hulke, F.R.C.S., Lieut.-General Sir Henry Lefroy, C.B., William Newmarch, Inst. Fr. Corr., Prof. Alfred Newton, M.A., V.P.Z.S., Prof. William Odling, M.B., V.P.C.S., Sir James Paget, Bart., D.C.L., William Henry Perkin, Sec. C.S., Charles William Siem ens, D.C.L., John Simon, C.B., D.C.L., Prof. John Tyndall, D.C.L., LL.D.

A MEMORIAL strongly recommending Lord Rayleigh's election (if he can be induced to become a candidate), to the Professorship of Experimental Physics at Cambridge, is in circulation. Lord Rayleigh's merits for such an appointment are perfectly well known to our readers. We understand that his election will be supported by many of the professoriate.

WE are pleased to hear that Prof. Sir Wyville Thomson is now much better, and able to conduct the correspondence in connection with the Challenger work.

THE death is announced, at Florence, of Miss Martha Charters Somerville, the only surviving daughter of Mrs. Mary Somerville, in her sixty-sixth year. Mis; Somerville enjoyed a pension of rool. a year, in recognition of the services rendered to science by her mother.

The Royal Institution Christmas Lectures will be given by Prof. Tyndall. The subjects will be Water and Air.

ON Tuesday night Dr. W. W. Hunter, the Indian DirectorGeneral of Statistics, delivered a lecture at the Philosophical Institution of Edinburgh, on the subject of "What the English had done for India." Contrasting the present English condition of the country with what it has become, since we have had to do with it. Dr. Hunter showed that the improvements in the land, and in the lot of the people had been immense. We need 